\title{
Noise reduction in ECG signals for bio-telemetry
}

\author{
V. Jagan Naveen ${ }^{1}$, K. Murali Krishna ${ }^{2}$, K. Raja Rajeswari ${ }^{3}$ \\ ${ }^{1}$ Department of Electronics and Communication Engineering, GMR Institute of Technology, Rajam, India \\ ${ }^{2}$ Department of ECE, ANITS, Vishakhapatnam, India \\ ${ }^{3}$ Department of ECE, GVPCEW, Vishakhapatnam, India
}

\begin{tabular}{|c|c|}
\hline Article Info & ABSTRACT \\
\hline Article history: & In Biotelemetry, Biomedical signal such as ECG is extremely important in \\
\hline Received Jun 19, 2018 & $\begin{array}{l}\text { the diagnosis of patients in remote location and is recorded commonly with } \\
\text { noise. Considered attention is required for analysis of ECG signal to find the }\end{array}$ \\
\hline Revised Sep 20, 2018 & patho-physiology and status of patient. In this paper, LMS and RLS \\
\hline Accepted Okt 11, 2018 & $\begin{array}{l}\text { algorithm are implemented on adaptive FIR filter for reducing power line } \\
\text { interference }(50 \mathrm{~Hz}) \text { and (AWGN) noise on ECG signals. The ECG signals }\end{array}$ \\
\hline Keywords: & $\begin{array}{l}\text { are randomly chosen from MIT_BIH data base and de-noising using } \\
\text { algorithms. The peaks and heart rate of the ECG signal are estimated. The }\end{array}$ \\
\hline $\begin{array}{l}\text { ECG signals } \\
\text { LMS algorithm }\end{array}$ & $\begin{array}{l}\text { measurements are taken in terms of Signal Power, Noise Power and Mean } \\
\text { Square Error. }\end{array}$ \\
\hline
\end{tabular}

Mean Square Error

power line interference

RLS algorithm

Copyright $@ 2019$ Institute of Advanced Engineering and Science. All rights reserved.

Corresponding Author:

V. Jagan Naveen,

Department of Electronics and Communication Engineering,

GMR Institute of Technology, Rajam, India.

Email: jagannaveen801@gmail.com

\section{INTRODUCTION}

The Electro Cardiogram (ECG) produces electrical signals of the each cardiac cycle. In the cardiac cycle each event has its own significance to study the behaviour of patient cardiac pathophysiology, Generally ECG signals are Bio electrical signal which gives the electrical activity of heart versus time. Therefore it is very important to diagnose for analysing heart function [1]. The Bio electrodes are placed on the skin of the patient to acquire ECG signals. The pacemakers are located in the upper part of the right atrium. It fires electrical pulses to the nerves to stimulate the contraction phase. These pulses extend over the atrial walls and activate cardiac muscles to contract. The ECG and power-line signal's frequency range is typically 0.05 to $100 \mathrm{~Hz}$ and $50 \mathrm{~Hz}$ so, ECG signals sensitive to the power line signals in the range around $50 \mathrm{~Hz}$ which are causing interference [2]. $50 \mathrm{~Hz}$ PLIN will interrupt the P and Q waves of the ECG signal. Most of Asian regions, Domestic and hospital power line are in the range of $50 \mathrm{~Hz}$. So the frequency components associated in ECG that is $50 \mathrm{~Hz}$ are effected by the power line signals causing interference in ECG. But lack of power line quality the power signals are swings between the 47 to $53 \mathrm{~Hz}$ so the interference also effects from this range of power line signal. To mitigate this dynamic interference from power line we need use adaptive filter to suppress this random noise causing from power line [3]. An adaptive noise elimination filter has been used to evade this impending loss of information. Four different waves can be observed while recording ECG signal those are PQRST. The depolarization of right atria represents P wave. While the rapid depolarization of right and left ventricles represents QRS wave. The repolarization of the ventricles represents $\mathrm{T}$ wave [4], [5]. Any deviation in the said parameters leads abnormalities in the heart. The wave form related to QRS complex represent the contraction of left and right ventricles, which is more powerful than that of atria .It comprises muscle mass and causing a more ECG deflection. The $\mathrm{Q}$ wave signifies the signal horizontal (i.e. left to right) current as a potential travel through the inter-ventricular system.The Q wave is not having a septal origin shows myocardial violation which involves the full depth of 
myocardium. The $\mathrm{P}$ wave arises when the SA node (Sinus Atria) generates a potential which depolarizes the atria.However as long as the atrial depolarization takes place to spread through the AV node to the ventricles, each $\mathrm{p}$ wave should be trailed by QRS complex [6]. From the commencement of QRS complex is called PR interval. This indicates the time that it takes for the electrical impulses produced in the SA node and to travel through the atria and across the AV node (Atria Ventricle) node to the ventricle. In adaptive filter, least mean square algorithm requires input signal and reference signal to update the (tap weights) filter coefficients of the adaptive FIR filter. For every iteration, LMS algorithm update new tap weights based on the previous tap weights to minimize the error. After several iterations, it eliminate the noise in the adaptive filter and gives best minimum mean square error. This method follows the computation based on the past available information. The RLS (recursive least square) algorithm gives better convergence than LMS algorithm[7].The main dis advantage of the RLS algorithm is having high computational cost. In the paper, Section 2 shows the LMS and RLS algorithm, Section 3 gives the simulation results and Section 4 gives the conclusion results.

\section{ADAPTIVE FILTERING}

Adaptive filter involves the alteration of filter parameters (coefficient) over time to reduce the noise in the signal and to minimize the error [8]. Digital signal processing exhibited by most of the adaptive filters will be digital in nature because of complexity in optimizing algorithms.Adaptive filters are best suited when there is large uncertainty and filter has to compensate that or signal conditions are slowly changing. The performance of adaptive filter involves two process, which are filter processing and adaptation process[9]. The adaptive filter output $\mathrm{Z}(\mathrm{n})$ is given as:

$$
\mathrm{Z}(\mathrm{n})=\mathrm{P}(\mathrm{n}) \mathrm{S}(\mathrm{n})
$$

where $\mathrm{S}(\mathrm{n})$ is the input ECG signal and $\mathrm{P}(\mathrm{n})$ are the adaptive filter coefficients.

As we known ECG signal interference by $50 \mathrm{~Hz}$ power line signal .so, we have to suppress the 50 $\mathrm{Hz}$ component in the ECG signal which are originated by the power line. If we remove complete $50 \mathrm{~Hz}$ component in the ECG signal there may be data loss in the ECG signal which are associated with $50 \mathrm{~Hz}$ frequencies region. So we need to estimate the disturbance by power line signal for that we giving power line signal as reference to the adaptive filter. Now the adaptive filter will track the power line components in ECG signal and we can easily extract interference part in the ECG signal.The difference between the desired signal $d(n)$ and the signal from the output of the filter $Z(n)$ is the error signal $e(n)$.

$$
\mathrm{e}(\mathrm{n})=\mathrm{d}(\mathrm{n})-\mathrm{Z}(\mathrm{n})
$$

The filter variable updates filter coefficients at every time instantaneous.

$$
\mathrm{P}(\mathrm{n}+1)=\mathrm{P}(\mathrm{n})+\Delta \mathrm{P}(\mathrm{n})
$$

Where $\mathrm{P}(\mathrm{n}+1)$ is the updated weight vector with the previous weight vector and $\Delta$ is the correction factor depends on the value.

\section{LEAST MEAN SQUARE ALGORITHM}

These algorithms was suggested by Widrow and Hoff. They developed LMS from their studies of pattern recognition [10]. In the LMS algorithms, the correction applied to the above mentioned estimate includes product of three factors: the error signal e $(n-1)$, the (scalar) step-size parameter $(\mu)$ and the tapinput vector s(n-1).LMS algorithm is the best selection if we are dealing with adaptive digital circuits in this case a filter that reject the bands of signal those causes interference to the ECG [11].The basic operation of LMS algorithm is the recursive updating nature of filter coefficients by the reference of error signal.

Each iteration of LMS involves three steps:

Filter output:

$$
\mathrm{Z}[\mathrm{n}]=\sum_{\mathrm{n}=0}^{\mathrm{N}-1} \mathrm{~S}[\mathrm{n}] \mathrm{P}[\mathrm{n}]
$$


Estimation error:

$$
e(n)=d(n)-Z(n)
$$

Tap-weight adaptation:

$$
\mathrm{P}[\mathrm{n}+1]=\mathrm{P}[\mathrm{n}]+\mu \mathrm{S}[\mathrm{n}] \mathrm{e}[\mathrm{n}]
$$

$\mathrm{d}(\mathrm{n})$ is taken as desired signal and $\mathrm{Z}(\mathrm{n})$ is the output response of the adaptive filter equation 4 shows the output response of the Filter with input signal $S(n)$ and filter coefficients $\mathrm{P}(\mathrm{n})$.

\section{RECURSIVE LEAST SQUARE ALGORITHM}

With supreme computational complexity, RLS is the fastest converging algorithm. It cancels maximum amount of noise by minimizing error with the fastest rate. So in this study, a tradeoff between computational complexity and convergence rate is done to attain the utmost noise free signal. The filter output and error function of RLS algorithm are shown in Equations (8) and (9).

$$
R(n)=\frac{\lambda^{-1} L(n-1) u(n-1)}{1+\lambda^{-1} u^{H} L(n-1) u(n)}
$$

Where $R(n)$ is the vector gain, $L(n)$ is the inverse correlation matrix, $u(n)$ is the buffered input vector and $\lambda^{-1}$ denotes the reciprocal of the exponential weighting factor. The filter output is:

$$
Z(n)=P^{T}(n-1) u(n)
$$

Error signal:

$$
e(n)=d(n)-Z(n)
$$

The updated coefficients as shown in equation:

$$
\begin{aligned}
& P(n)=P(n-1)+R^{H}(n) e(n) \\
& P(n)=P(n-1)+R^{H}(n)[d(n)-Z(n)] \\
& P(n)=P(n-1)+R^{H}(n)\left[d(n)-P^{T}(n-1) S(n)\right]
\end{aligned}
$$

where $\mathrm{R}^{\mathrm{H}}(\mathrm{n})$ is the gain constant, with a sequence of training data up to time, the RLS algorithm estimates the weight by minimizing the resulting cost [13].where $u(n)$ is the input, and $\lambda$ is the stabilization parameter.

\section{RESULTS AND ANALYSIS}

ECG signals are randomly taken from MIT_BIH data base i.e. $(101,104,106,109,124)$ [14]-[16].The length of each ECG signal is restricted to 3600 samples. In LMS algorithm the mu is taken as 0.02 and in RLS algorithm lambda is taken as one randomly.Matlab is taken as a tool for simulations and noise is considered as Adaptive White Gaussian Noise (AWGN) with power line interference of $50 \mathrm{~Hz}$ on ECG signal with less noise power. After de-noising using LMS and RLS algorithm, ECG signals peaks are estimated and results are compared with original signals without noise.

3.1 Implementation of LMS Algorithm by reducing channel Noise and reducing Power line interference of $50 \mathrm{~Hz}$ in ECG Signal Shown in Figure 1 to Figure 7 and Table 1 to Figure 10. 


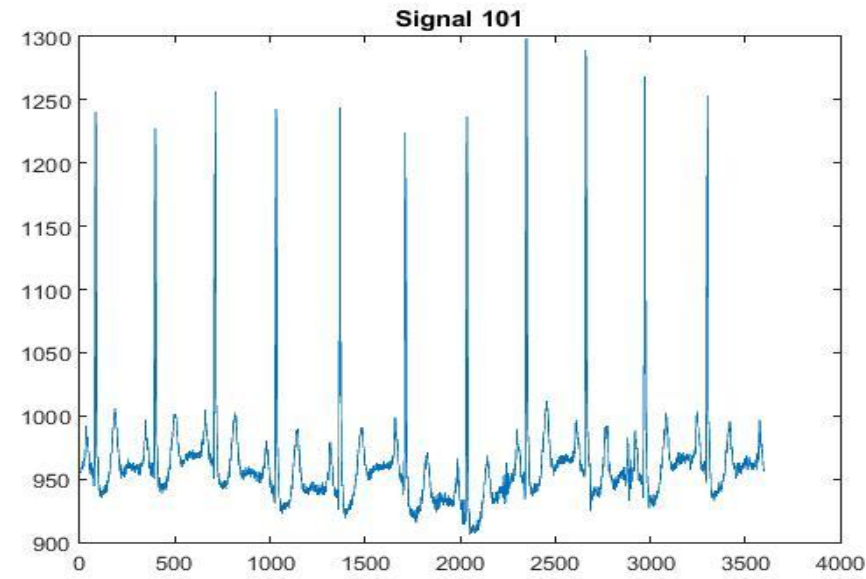

Figure 1. ECG waveform from MIT-BIH database

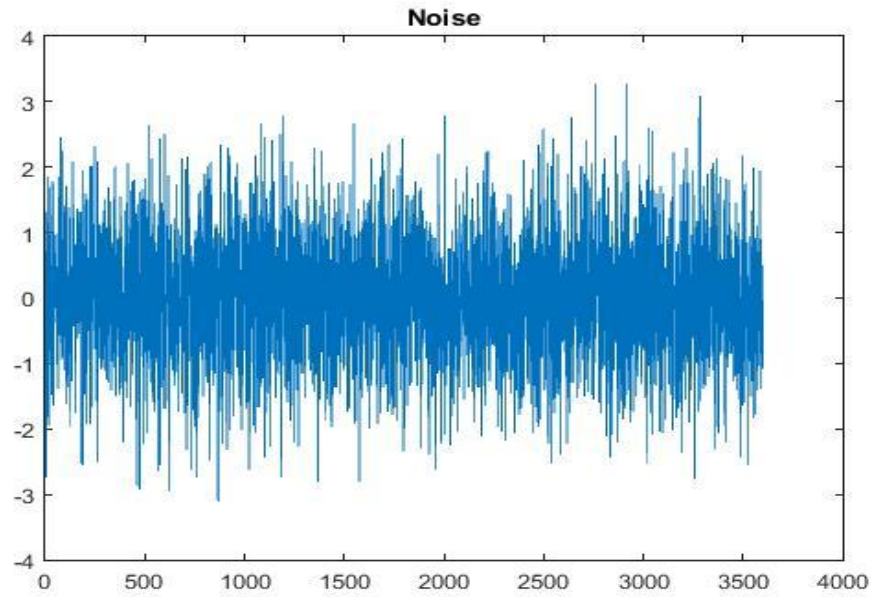

Figure 2. Noise signal

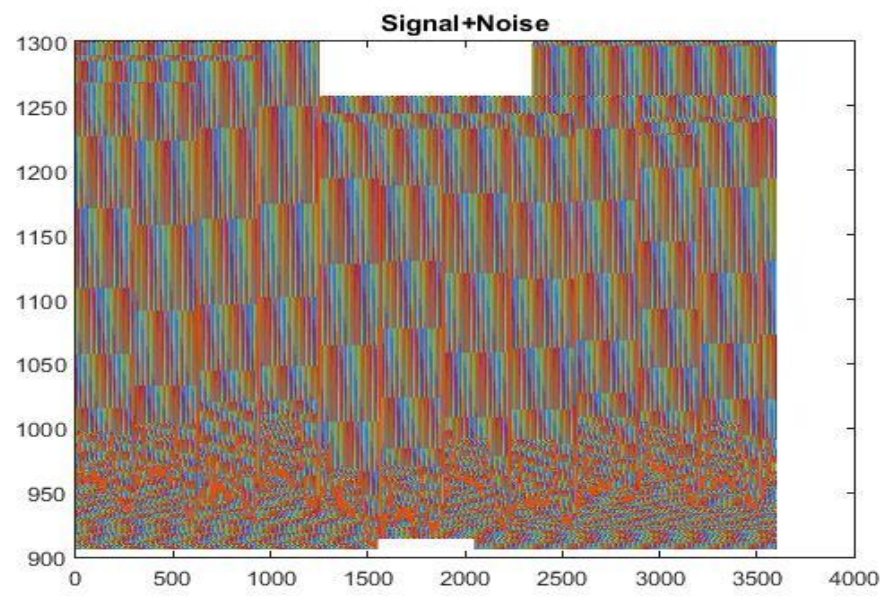

Figure 3. ECG signal + noise 


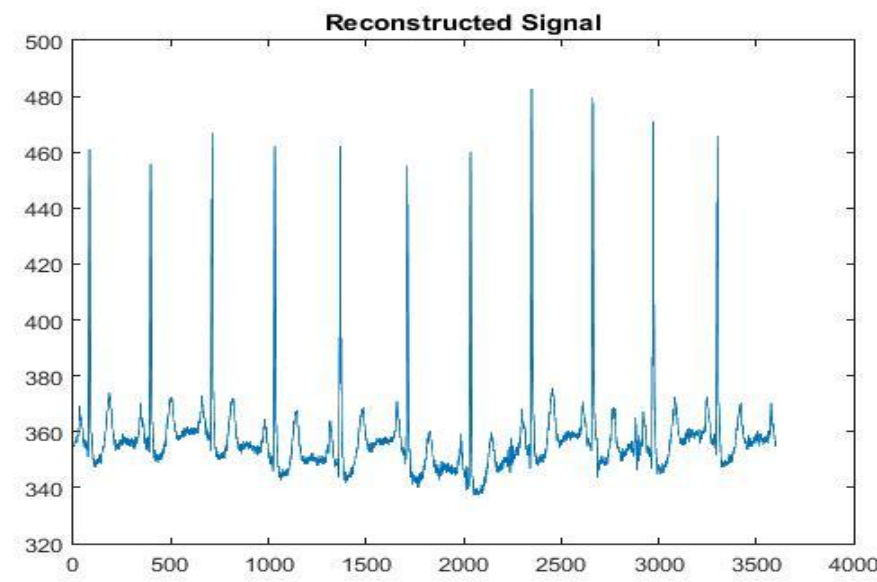

Figure 4. Noise removal in ECG Signal using LMS algorithm

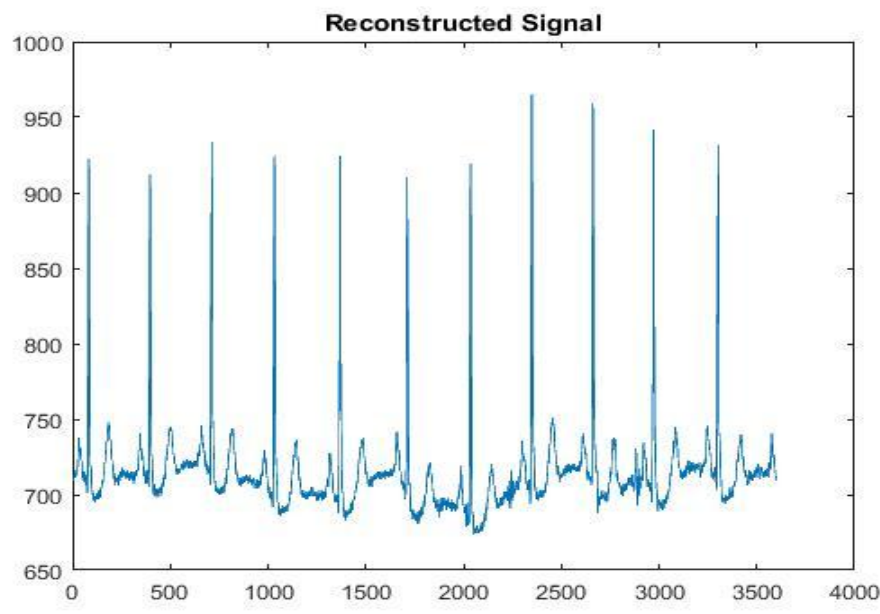

Figure 5. (50Hz) Power Line Interference suppression using LMS Algorithm

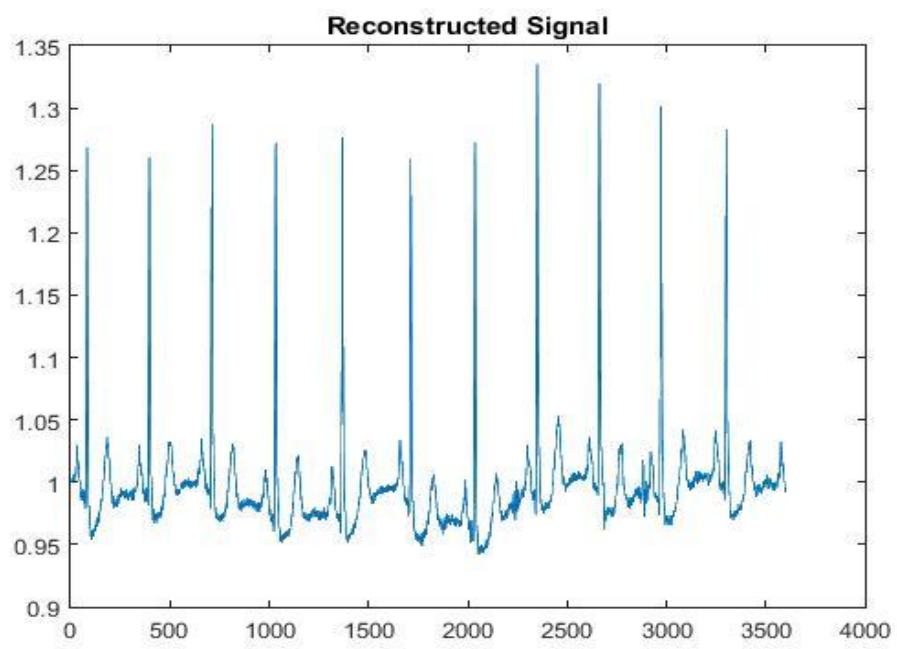

Figure 6. Noise removal in ECG Signal using LMS algorithm 


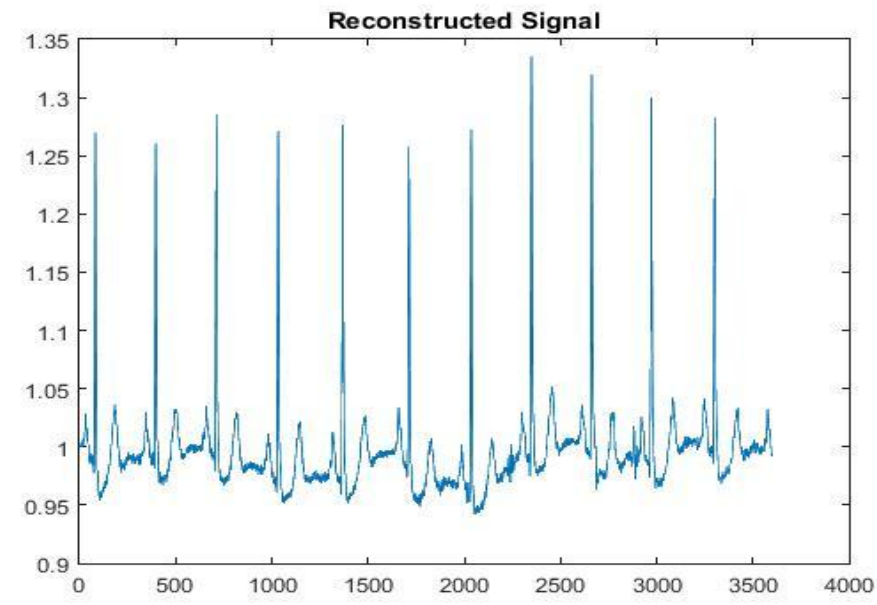

Figure 7. (50Hz) Power Line Interference suppression using RLS Algorithm

Table 1. Channel noise reduction on ECG signal using LMS algorithm by considering interference of the same signal by ith different phase in the channel with $\mathrm{mu}=0.02$ taken randomly

\begin{tabular}{ccccc}
\hline $\begin{array}{c}\text { Signals from MIT_BIH } \\
\text { data base }\end{array}$ & $\begin{array}{c}\text { ECG Signal Power } \\
(\mathrm{dB})\end{array}$ & $\begin{array}{c}\text { Noise Signal Power } \\
(\mathrm{dB})\end{array}$ & $\begin{array}{c}\text { Power of the Error Signal } \\
(\mathrm{dB})\end{array}$ & $\begin{array}{c}\text { Mean Square deviation } \\
(\mathrm{dB})\end{array}$ \\
\hline 101 & -0.3339 & 0.0843 & -8.9620 & -21.2726 \\
104 & -0.1954 & 0.1034 & -8.7943 & -21.0287 \\
106 & -0.0922 & 0.0702 & -8.6967 & -21.0243 \\
109 & -0.4866 & 0.0771 & -9.1009 & -21.0891 \\
124 & -1.2148 & -0.032 & -9.8297 & -22.5220 \\
\hline
\end{tabular}

Table 2. Power line interference of $50 \mathrm{~Hz}$ on ECG signal by reducing interference using LMS algorithm by considering interference of the same signal by the different phase in the channel

\begin{tabular}{cccccc}
\hline $\begin{array}{c}\text { Types of Signal from } \\
\text { MIT_BIH } \\
\text { data base }\end{array}$ & $\begin{array}{c}\text { ECG signal } \\
\text { Power } \\
(\mathrm{dB})\end{array}$ & $\begin{array}{c}\text { Noise signal } \\
\text { Power } \\
(\mathrm{dB})\end{array}$ & $\begin{array}{c}\text { Power of the Signal } \\
\text { and Noise } \\
(\mathrm{dB})\end{array}$ & $\begin{array}{c}\text { Power of the Error } \\
\text { Signal } \\
(\mathrm{dB})\end{array}$ & $\begin{array}{c}\text { Mean Square } \\
\text { deviation } \\
(\mathrm{dB})\end{array}$ \\
\hline 101 & -0.3339 & -3.010 & 5.6820 & -2.9158 & -29.044 \\
104 & -0.1954 & -3.010 & 5.8206 & -2.7737 & -28.8041 \\
106 & -0.0922 & -3.010 & 5.9218 & -2.6680 & -28.7976 \\
109 & -0.4866 & -3.010 & 5.5267 & -3.0627 & -28.8639 \\
124 & -1.2148 & -3.010 & 4.8001 & -3.7882 & -30.2965 \\
\hline
\end{tabular}

Table 3. Channel noise reduction on ECG signal using RLS algorithm by considering interference of the same signal by ith different phase in the channel with $\lambda=1$ taken randomly

\begin{tabular}{cccc}
\hline $\begin{array}{c}\text { Signals from MIT-BIH Arrhythmia } \\
\text { data base }\end{array}$ & $\begin{array}{c}\text { ECG signal Power } \\
(\mathrm{dB})\end{array}$ & $\begin{array}{c}\text { Noise signal Power } \\
(\mathrm{dB})\end{array}$ & $\begin{array}{c}\text { Power of the errorSignal } \\
(\mathrm{dB})\end{array}$ \\
\hline 101 & -0.3339 & -0.0467 & -0.0274 \\
104 & -0.1954 & -0.0472 & -0.0581 \\
106 & -0.0922 & -0.1854 & -0.0630 \\
109 & 0.4866 & -0.2264 & 0.0268 \\
124 & -1.2148 & -0.0494 & 0.0065 \\
\hline
\end{tabular}

Table 4. Power line interference of $50 \mathrm{~Hz}$ on ECG signal by reducing interference using RLS algorithm by considering interference of the same signal by the different phase in the channel

\begin{tabular}{ccccc}
\hline $\begin{array}{c}\text { Signal from MIT- } \\
\text { BIH data base }\end{array}$ & $\begin{array}{c}\text { Power of the original ECG } \\
\text { signal }(\mathrm{dB})\end{array}$ & $\begin{array}{c}\text { Noise signal } \\
\text { Power }(\mathrm{dB})\end{array}$ & $\begin{array}{c}\text { Power of the Signal and } \\
\text { Noise }(\mathrm{dB})\end{array}$ & $\begin{array}{c}\text { Power of the Error Signal } \\
(\mathrm{dB})\end{array}$ \\
\hline 101 & -0.3339 & -3.0103 & 5.6879 & -0.0274 \\
104 & -0.1954 & -3.0103 & 5.8274 & -0.0581 \\
106 & -0.0922 & -3.0103 & 5.9320 & -0.0630 \\
109 & -0.4866 & -3.0103 & 5.5360 & 0.0268 \\
124 & -1.2148 & -3.0103 & 4.8114 & 0.0065 \\
\hline
\end{tabular}

Table 5. Estimation signal power in time and frequency domain for the Signals from MIT-BIH 


\begin{tabular}{ccc}
\hline $\begin{array}{c}\text { Signals from MIT-BIH } \\
\text { Arrhythmia data base }\end{array}$ & Power Time domain $(\mathrm{dB})$ & Power Frequency domain $(\mathrm{dB})$ \\
\hline 101 & -0.3327 & -0.3938 \\
104 & -0.1932 & -0.1920 \\
106 & -0.0886 & -0.0801 \\
109 & -0.4845 & -0.5635 \\
124 & -1.2092 & -0.9733 \\
\hline
\end{tabular}

Table 6. Each ECG signal's length is having 3600 samples under noise less conditions, QRST peaks are estimated in ECG signals as shown in the table $(\mathrm{mV})$

\begin{tabular}{cccccc}
\hline $\begin{array}{c}\text { Signal from } \\
\text { MIT-BIH data base }\end{array}$ & R Peak $(\mathrm{mV})$ & S Peak $(\mathrm{mV})$ & T Peak $(\mathrm{mV})$ & Q Peak (mV) & $\begin{array}{c}\text { Heart Rate } \\
\text { beats/min }\end{array}$ \\
\hline 101 & 203.23 & -25.535 & 35.965 & -6.672 & 45.83 \\
104 & 266.12 & 3.458 & 259.47 & 141.616 & 58.33 \\
106 & 355.24 & -26.902 & 145.803 & 115.92 & 54.16 \\
109 & 256.372 & 23.832 & 208.24 & 163.611 & 66.66 \\
124 & 390.59 & -41.245 & 20.3103 & 102.8 & 33.33 \\
\hline
\end{tabular}

Table 7. LMS algorithm is taken on noisy ECG signals which are corrupted with additive white gaussian noise. QRST peaks are measured $(\mathrm{mV})$

\begin{tabular}{cccccc}
\hline $\begin{array}{c}\text { Signals from MIT- } \\
\text { BIH data base }\end{array}$ & R Peak $(\mathrm{mV})$ & S Peak $(\mathrm{mV})$ & T Peak $(\mathrm{mV})$ & Q Peak (mV) & $\begin{array}{c}\text { Heart Rate } \\
\text { beats/min }\end{array}$ \\
\hline 101 & 75.65 & -9.469 & 13.200 & -2.706 & 55.83 \\
104 & 98.99 & 1.317 & 96.503 & 52.671 & 58.33 \\
106 & 132.36 & -9.690 & 54.309 & 42.87 & 60.49 \\
109 & 94.71 & 8.86 & 77.436 & 38.16 \\
124 & 145.15 & -15.42 & 7.398 & 36.66 \\
\hline
\end{tabular}

Table 8. LMS algorithm is introduced on signal of ECG to minimize the $50 \mathrm{~Hz}$ power line interference on ECG system for considering $\mathrm{mu}=0.02$.The readings are taken in terms of milli volts as shown in the table

\begin{tabular}{cccccc}
\hline $\begin{array}{c}\text { Signal from MIT-BIH } \\
\text { Arrhythmia data base }\end{array}$ & R Peak $(\mathrm{mV})$ & S Peak $(\mathrm{mV})$ & T Peak $(\mathrm{mV})$ & Q Peak (mV) & $\begin{array}{c}\text { Heart Rate } \\
\text { beats/min }\end{array}$ \\
\hline 101 & 75.745 & -9.571 & 13.242 & -2.392 & 45.83 \\
104 & 98.855 & 1.691 & 96.343 & 52.503 & 58.33 \\
106 & 132.288 & -9.827 & 54.395 & 42.822 & 54.16 \\
109 & 96.264 & 8.813 & 77.511 & 61.396 & 66.66 \\
124 & 144.994 & -15.207 & 7.584 & 38.137 & 33.33 \\
\hline
\end{tabular}

Table 9. RLS algorithm is taken on noisy ECG signals to reduce AWGN noise on the noisy ECG signals. Readings are taken for different signals inMIT data base and measurements are in milli volts

\begin{tabular}{|c|c|c|c|c|c|}
\hline $\begin{array}{c}\text { Signal from MIT-BIH } \\
\text { Arrhythmia } \\
\text { data base }\end{array}$ & R Peak $(\mathrm{mV})$ & S Peak (mV) & T Peak (mV) & Q Peak $(\mathrm{mV})$ & $\begin{array}{l}\text { Heart Rate } \\
\text { beats/min }\end{array}$ \\
\hline 101 & 0.208 & -0.027 & 0.036 & -0.003 & 45.83 \\
\hline 106 & 0.341 & -0.029 & 0.144 & 0.112 & 54.16 \\
\hline 109 & 0.261 & 0.027 & 0.214 & 0.161 & 66.66 \\
\hline 124 & 0.446 & -0.047 & 0.024 & 0.115 & 33.33 \\
\hline
\end{tabular}

Table 10. RLS algorithm is considered to remove power line interference on the ECG signals which are interfered with $50 \mathrm{~Hz}$ power line frequency in the system. volts

\begin{tabular}{cccccc}
\hline $\begin{array}{c}\text { Signal from MIT-BIH } \\
\text { Arrhythmia data base }\end{array}$ & R Peak $(\mathrm{mV})$ & S Peak $(\mathrm{mV})$ & T Peak $(\mathrm{mV})$ & Q Peak (mV) & $\begin{array}{c}\text { Heart Rate } \\
\text { beats/min }\end{array}$ \\
\hline 101 & 0.2089 & -0.0275 & 0.0371 & -0.0035 & 45.83 \\
104 & 0.2660 & 0.0032 & 0.2702 & 0.1406 & 58.33 \\
106 & 0.3412 & -0.0299 & 0.1447 & 0.1056 & 54.16 \\
109 & 0.2623 & 0.0272 & 0.2142 & 0.1611 & 66.66 \\
124 & 0.4459 & -0.0472 & 0.0246 & 0.1154 & 33.33 \\
\hline
\end{tabular}

By observing Table 6 to Table 10 power line interference $(50 \mathrm{~Hz})$ in the system and noise in the channel are suppressed to maximum extend using LMS and RLS algorithm.The peaks of QRST in ECG waves and heart rates are measured for different signals from MIT _BIH data base. 


\section{CONCLUSION}

In this paper, the ECG signals are taken from physio-net for analysis. For Bio-telemetry applications, signals are transmitted from remote locations, LMS and RLS adaptive algorithms are considered for suppression of AWGN noise and power line interference on ECG signals. The analysis is carried out to evaluate the ECG signal power, noise signal and Mean square error. It is observed that Mean square error is less in RLS then LMS. Noise cancellation capacity is good in RLS than LMS. But the implementation is complex over LMS.After denoising at the receiver end, QRST peaks and heart beats are estimated and compared with the original QRST peaks and heart beats.

\section{REFERENCES}

[1] Jan Adamec, Richard Adamec, Lukas Kappen berger and Philippe Coumel, "ECG Holter: Guide to Electrocardiographic Interpretation”, 2008 edition, springer science+business media, LLC, New York, ISBN-978-0-387-78186-0.Issn (Print): 2231 - 5284, Vol-2, Iss-1, (2012).

[2] Y. Der Lin and Y. Hen Hu, "Power-Line Interference Detection and Suppression in ECG Signal Processing," IEEE Trans. Biomed. Eng., Vol. 55, Pp. 354-357, Jan. (2008).

[3] Sushanta Mahanty, "Control and Estimation of Biological Signals (ECG) Using Adaptive System," International Journal of Electrical and Electronics Engineering (IJEEE).

[4] C. Li and C. Zheng, "QRS Detection by Wavelet Transform", in Proceedings of Annual International Conference on IEE Eng. in Med. \& Biol. Soc., San Diego, California,( 1993).

[5] Ravi Kumar Jatoth, Saladi S.V.K.K. Anoop and Ch. Midhun Prabhu, "Biologically Inspired Evolutionary Computing tools for the Extraction of Fetal Electrocardiogram", WSEAS Transactions on Signal Processing, 5, No. 3, pp. 106-115, March (2009).

[6] Lome D.O, Learn the Heart, Complete Cardiology in a Heartbeat, (2003), online souce avaliable at: http://www.learntheheart.com.

[7] K. Muhsin; "Comparison of the RLS and LMS Algorithms to Remove Power Line Interference Noise from ECG Signal," Al-Khwarizmi Engineering Journal, Vol. 6, No. 2, PP 51- 61 (2010).

[8] V. Jagan Naveen , J. Venkata Suman and P.Devi Pradeep "Noise suppression in speech signals using adaptive filter," International journal of signal processing, images processing and pattern recognition, volume 3 issue 3 page no: 87.96,published by SERSC South Korea.

[9] Simon Haykin, "Adaptive Filter Theory," Fourth Edition, Prentice Hall, Inc (2002).

[10] W. Kenneth Jenkins, Andrew W. Hull, Jeffrey C. Strait, Bernard A. Schnaufer, XiaohuiLi, "Advanced Concept in Adaptive Signal Processing," Kluwer Academic Publisher (1996).

[11] N. Kalouptsidis, "Adaptive System Identification and Signal Processing Algorithm," (University of Athens) and S. Theodoridis (University of Patras) Prentice Hall Inc.,(1993).

[12] A. Buades, B. Coll, and J. M. Morel, "A Review of Image Denoising Algorithms, With A New One," Multiscale Modeling AndSimulation, Vol. 4, No. 2, Pp. 490-530, (2005).

[13] Huang, Y.J. Wang, Y.W. Meng, F.J. Wang, G.L., "A spatial spectrum estimation algorithm based on adaptivebeam forming nulling," Intelligent Control and Information Processing (ICICIP), 2013 Fourth International Conference, pp. 220 - 224, June (2013).

[14] Mark RG, Schluter PS, Moody GB, Devlin, PH, Chern off, D., "An annotated ECG database for evaluating arrhythmia detectors," IEEE Transactions on Biomedical Engineering 29(8):600 (1982).

[15] Moody GB, Mark RG. The MIT-BIH Arrhythmia Database on CD-ROM and software for use with it. Computers in Cardiology 17:185-188 (1990).

[16] http://www.physionet.org/physio bank / database/mit db. 